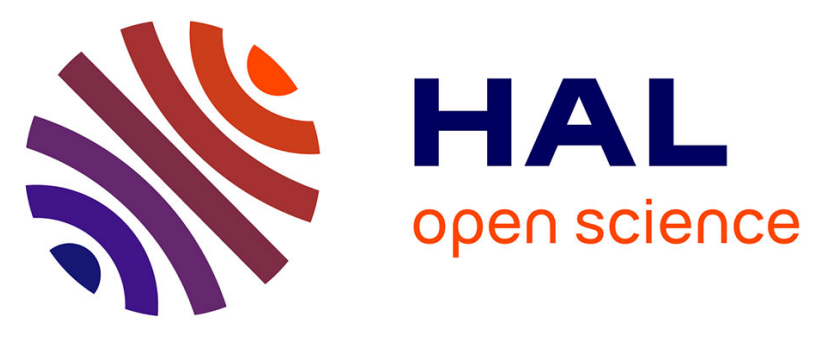

\title{
Comparison Between Numerical and Analytical Methods of AC Resistance Evaluation for Medium Frequency Transformers: Validation on a Prototype
}

Albert Pereira, Bruno Lefebvre, Fabien Sixdenier, Marie-Ange Raulet, Noël Burais

\section{To cite this version:}

Albert Pereira, Bruno Lefebvre, Fabien Sixdenier, Marie-Ange Raulet, Noël Burais. Comparison Between Numerical and Analytical Methods of AC Resistance Evaluation for Medium Frequency Transformers: Validation on a Prototype. 2015 IEEE EPEC, Oct 2015, London, ON, Canada. 10.1109/EPEC.2015.7379938 . hal-01374145

\author{
HAL Id: hal-01374145 \\ https://hal.science/hal-01374145
}

Submitted on 29 Sep 2016

HAL is a multi-disciplinary open access archive for the deposit and dissemination of scientific research documents, whether they are published or not. The documents may come from teaching and research institutions in France or abroad, or from public or private research centers.
L'archive ouverte pluridisciplinaire HAL, est destinée au dépôt et à la diffusion de documents scientifiques de niveau recherche, publiés ou non, émanant des établissements d'enseignement et de recherche français ou étrangers, des laboratoires publics ou privés. 


\section{Comparison Between Numerical and Analytical Methods of AC Resistance Evaluation for Medium Frequency Transformers: Validation on a Prototype}

\author{
A. PEREIRA, B. LEFEBVRE \\ SuperGrid Institute \\ 130 rue Léon Blum, Villeurbanne, \\ 69100 FRANCE
}

\author{
A.PEREIRA, F. SIXDENIER, M. A. RAULET, N. \\ BURAIS \\ Université de Lyon, Université de Lyon 1 CNRS UMR5005 \\ AMPERE, 43, Bld du 11 Novembre 1918, Villeurbanne, \\ 69622 FRANCE
}

\begin{abstract}
In the future, Medium Frequency Transformers (MFT with a frequency range $5 \mathrm{kHz}$ to $100 \mathrm{kHz}$ ) will be major components in DC-DC converter applications, for both Medium Voltage Direct Current (MVDC) and High Voltage Direct Current (HVDC) networks. Importantly, the corresponding power losses should be accurately calculated in order to reach performance targets (very high efficiency). This paper reviews the most known analytical models which are used to calculate the medium frequency resistance for several winding technologies. In order to qualify these models in a future design flow, we compare the analytical model results with measurements and 3D finite element (3DFE) electromagnetic simulations. The adopted design flow-chart has been tested on a $17 \mathrm{kHz}-180 \mathrm{kVA}$ prototype transformer that will be used in a Dual Active Bridge (DAB).
\end{abstract}

Index Terms--DC-DC power converters, Numerical simulation, Power transformers, Proximity effects.

\section{INTRODUCTION}

One approach to limit global $\mathrm{CO}_{2}$ emissions is to increase the generation of renewable energy, for example, by way of offshore wind farms or solar panels. The European Union has set as a target to increase $20 \%$ by 2020 the proportion of renewable energy generation ( $23 \%$ for France). New offshore wind projects are in development in order to help meet the renewable energy targets. The main drawback with renewable energy generation, when the generator is in a remote location, is that the power transmission distance can exceed an efficiency threshold (e.g. 80/100 km). In this last case, HVDC is the most promising solution to minimize the transmission losses [1].

Nowadays, the technological advances in the power electronics field, allows the voltage levels in HVDC networks to be adjusted. Indeed, recent researches showed that Silicon Carbide ( $\mathrm{SiC}$ ) semiconductors can operate at higher voltages than Silicon (Si) semiconductors [2].
The Dual Active Bridge (DAB) can be used to manage the energy transfer [3] between two DC voltage levels. It consists of two full-bridge converters separated by a medium frequency transformer (see Fig. 1). This type of converter allows power to flow bidirectionally. When designing an MFT with high efficiency, a design flow-chart, similar to the one presented in [4], can be used.

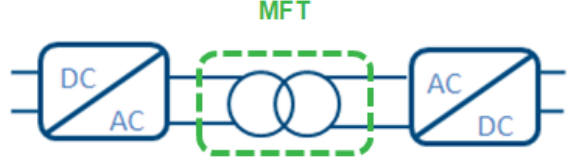

Figure 1. Dual Active Bridge

In many power electronic converter applications, the current waveform is non-sinusoidal, containing a fundamental component and also many harmonics. The DAB can be regulated with the phase shift between the voltages generated by the two full bridges, it corresponds to the rectangular modulation presented in Fig. 2 (using Simplorer ${ }^{\circledR}$ [5]). This leads to an increase of the equivalent alternative resistance (1).

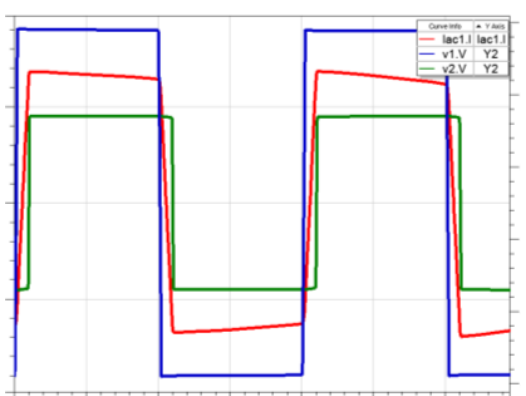

Figure 2. DAB rectangular modulation (Iac1: primary current (red), V1 and V2 are respectively voltage generated by the primary (blue) and secondary (green) bridge)

Many research studies [6]-[8] have been carried out to propose analytical models which able to predict accurately the AC resistance $R_{A C}$. But, the limits of the analytical models 
must be established before incorporating them into the design flow-chart.

Many works [9], [10] have been carried out to determine the limits of the different theoretical models. These works changed only a limited number of parameters and the discrepancies between their measurements and analytical models suffered from a lack of explanations.

In this paper, several analytical models to calculate $R_{A C}$ are studied in section II.

In section III, some comparisons are carried out between numerical and analytical methods regarding the influence of different technological parameters.

Then, the analytical model results are compared with measurements results and with 3DFE calculations (using Maxwell 3D ® with Eddy Current solver [5]) in section IV. These comparisons are also made in order to check and explain the differences observed between analytical models and measurements. And then, the most effective model (analytical or numerical), will be incorporated into the design flow-chart. Finally, in section V, in order to check the adopted design flow-chart, an MFT prototype has been designed. Magnetic losses, which are another important part of the design flow-chart are not studied in this paper.

\section{ANALYTICAL MODELS For FoIL, ROUND WIRE WINDING}

In many power electronic converter applications, the current waveform is non-sinusoidal containing a fundamental component and also many harmonics. In order to calculate the winding losses, for a non-sinusoidal current, the conductor losses can be estimated for each harmonic. By taking, $\mathrm{Fr}=R_{A C} / R_{D C}$ corresponding to the increase of the alternative resistance compared to the continuous resistance for each harmonic. The $F r_{\text {total }}$ which contains all the harmonics for a non-sinusoidal current is defined by (1).

$$
F r_{\text {total }}=\frac{I_{D C}{ }^{2}+\sum_{v=1}^{\infty} F r_{v} I_{v}{ }^{2}}{I_{D C}{ }^{2}+\sum_{v=1}^{\infty} I_{v}{ }^{2}}
$$

Where $I_{D C}$ is the DC component and $v$ is the harmonic number.

The analytical models presented in this paper are based on the following assumptions:

- It is a one dimensional problem,

- The magnetic flux between two layers winding is parallel to the core column,

- The considered Magneto Motive Force (M.M.F) is as presented in Fig. 3,

- The permeability of the core is infinite.

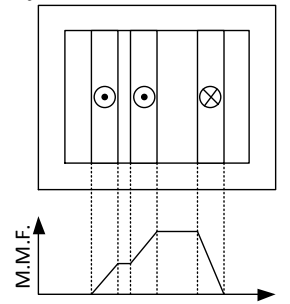

Figure 3. Transformer magneto motive force diagram

\section{A. DOWELL's model}

The most known analytical equation to evaluate $R_{A C}$ is the one given in [6]. Dowell introduced the concept of porosity coefficient in order to take into account the filling of the height of the winding window. Moreover, thanks to this coefficient, we can use this method to calculate losses in conductors for different winding technologies, by doing some transformations presented in Fig. 4. The equation (4) calculates $\mathrm{Fr}$ for each harmonic. In (4), some of the parameters have to be calculated before with (2) and (3).

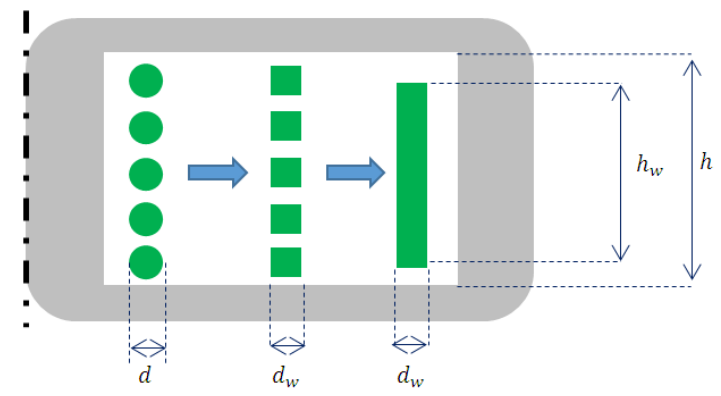

Figure 4. Round wire transformation to an equivalent foil

The first step is to transform the round wire into a square one while keeping the same effective area of the conductor:

$$
d_{w}=\sqrt{\frac{\pi}{4}} d
$$

The second step is to transform the square wire into an equivalent foil, always keeping the same effective area of the foil. Following this, the $\eta_{w}$ porosity coefficient is defined by (3).

$$
\eta_{w}=\frac{h_{w}}{h}
$$

Finally, the DOWELL's equation is:

$$
\begin{gathered}
F r=X^{\prime} \cdot\left[\frac{\sinh \left(2 X^{\prime}\right)+\sin \left(2 X^{\prime}\right)}{\cosh \left(2 X^{\prime}\right)-\cos \left(2 X^{\prime}\right)}\right. \\
\left.+\frac{2}{3}\left(m^{2}-1\right) \frac{\sinh \left(2 X^{\prime}\right)-\sin \left(2 X^{\prime}\right)}{\cosh \left(2 X^{\prime}\right)+\cos \left(2 X^{\prime}\right)}\right]
\end{gathered}
$$

Where $X^{\prime}=d / \delta \cdot \sqrt{\eta_{w}}$ is the ratio between the conductor or foil thickness $(d)$, the skin depth $(\delta)$ and $m$ is the number of layers.

\section{B. FERREIRA's model}

In [7], Ferreira proposes another equation to calculate the Fr coefficient, this new equation is based on solving Maxwell's equations using the Kelvin-Bessel functions. The proposed equation is:

$$
\begin{array}{r}
F r=\frac{\gamma}{2} \cdot\left[\frac{\operatorname{ber}(\gamma) b e i^{\prime}(\gamma)-b e i(\gamma) b e r^{\prime}(\gamma)}{b e r^{\prime 2}(\gamma)+b e i^{\prime 2}(\gamma)}\right. \\
\left.-2 \pi(2 . m-1)^{2} \cdot \frac{\operatorname{ber}_{2}(\gamma) b \operatorname{br}^{\prime}(\gamma)+b e i_{2}(\gamma) b e i^{\prime}(\gamma)}{b e r^{2}(\gamma)+b e i^{2}(\gamma)}\right]
\end{array}
$$


Where $\gamma=\frac{d}{\delta \sqrt{2}}$ and $\mathrm{d}$ is the wire diameter. We can note that this author does not take into account the porosity coefficient.

\section{REATTI's and KAZIMIERCZUK's model}

In [8], the authors propose another equation based on solving Maxwell's equations using the Kelvin-Bessel functions. This equation is often called the FERREIRA modified equation. The proposed equation is as follows:

$$
\begin{aligned}
F r=\frac{\gamma}{2} \cdot[ & \frac{\operatorname{ber}(\gamma) b e i^{\prime}(\gamma)-b e i(\gamma) b e r^{\prime}(\gamma)}{b \operatorname{cr}^{\prime 2}(\gamma)+b e i^{\prime 2}(\gamma)} \\
& -2 \pi \eta_{w}{ }^{2}\left(\frac{4\left(m^{2}-1\right)}{3}\right. \\
& \left.+1) \frac{\operatorname{ber}_{2}(\gamma) b e r^{\prime}(\gamma)+b e i_{2}(\gamma) b e i^{\prime}(\gamma)}{b e r^{2}(\gamma)+b e i^{2}(\gamma)}\right]
\end{aligned}
$$

Where $\gamma=\frac{d}{\delta \sqrt{2}}$ and $\mathrm{d}$ is the wire diameter. We can note that this author uses the porosity coefficient.

\section{INFLUENCE OF DIFFERENT TECHNOLOGICAL PARAMETERS}

For this section, different technological parameters were studied: influence of the connection, influence of the porosity coefficient and the distance between primary and secondary winding. For these preliminary calculations, the frequency range is $\mathrm{DC}$ to $20 \mathrm{kHz}$.

\section{A. Influence of the connections}

In order to study the influence of the connections, 3D finite element simulations were carried out with and without connections with a foil. The characteristics of the windings are: $h_{w}=50 \mathrm{~mm}$ and $200 \mathrm{~mm}, d=0.15 \mathrm{~mm}$ and $m=3$ turns.

\section{1) Without connections}

In this case, there are no connections; each turn is modelled by an independent coil. Thus, the current is imposed in each turn. This modelling is presented in Fig. 5.

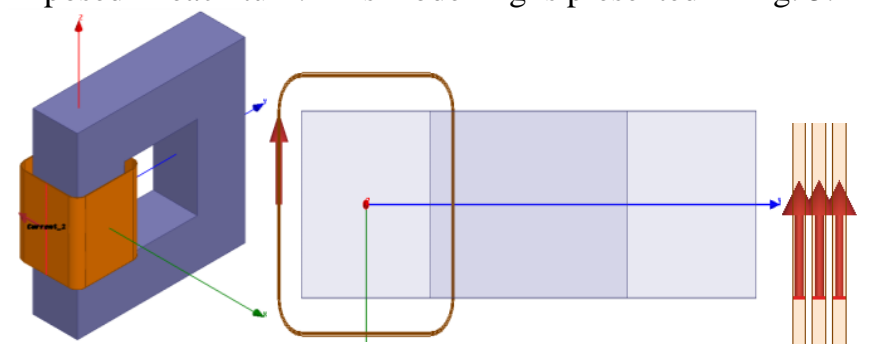

Figure 5. Global view of the transformer (left), top view of the transformer (middle) and a zoom on where the current is injected (right)

These simulation conditions are the ones that respect the most the analytical models assumptions, because the current is directly imposed and is the same in each layer. For a foil, with $h_{w}=50 \mathrm{~mm}$ and $200 \mathrm{~mm}$, the relative errors between 3 DFE simulations and theoretical models are less than $1 \%$, with a small distance between primary and secondary winding $(1 \mathrm{~mm}), \mathrm{DC}$ to $20 \mathrm{kHz}$.

\section{2) With connections}

In this case, there are connections; the coil is modelled by a "real" winding. Thus, the current is imposed in the connection. This modelling is presented in Fig. 6. The current distribution is not the same in each layer due to the connections.
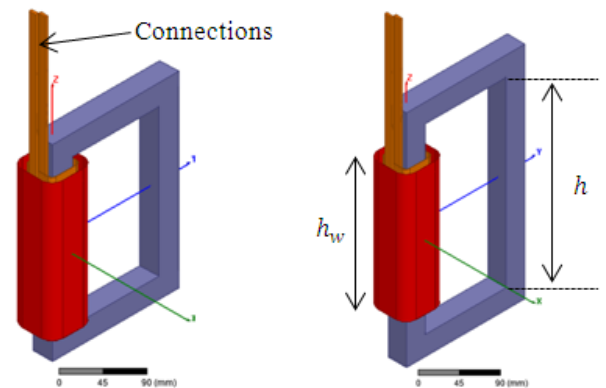

Figure 6. Construction of primary and secondary winding (orange and red) and core (grey) for different porosity factor respectively 0.93 (left) and 0.7 (right)

For a foil, with $h_{w}=50 \mathrm{~mm}$ and $200 \mathrm{~mm}$, the relative errors are presented in Table I.

TABLE I. RELATIVE ERRORS SimULATIONS WITH CONNECTIONS

\begin{tabular}{|l|l|}
\hline$h_{w}(\mathrm{~mm})$ & Relative error \\
\hline 50 & $\sim 5 \%$ \\
\hline 200 & $\begin{array}{l}\sim 60 \% \\
\text { (Maximum @ 20 kHz) }\end{array}$ \\
\hline
\end{tabular}

For a given foil thickness, if the height of the foil increases, the discrepancies between 3DFE and theoretical model results increases. The reason is that the current cannot spread uniformly throughout the height of the foil (See Fig. 7).

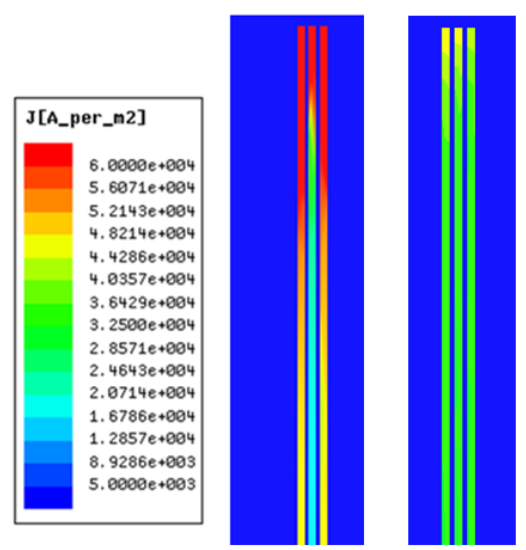

Figure 7. The current density @ $20 \mathrm{kHz}, h_{w}=200 \mathrm{~mm}$ (left) and $50 \mathrm{~mm}$ (right) with the same scale (Imposed current density is equal to $33 \mathrm{kA} \cdot \mathrm{m}^{-2}$ )

\section{B. Influence of the porosity coefficient and the distance between primary and secondary winding}

In our applications, the medium frequency transformer is destined for high power and high voltage, so it requires high 
voltage insulation between the primary and the secondary and also between the windings and the magnetic circuit. This could result in a "high" distance between the two windings and between the magnetic circuit and the coils. The distance between the primary and the secondary winding is not taken into account in the different analytical equations. In order to study the influence of these parameters, 3D finite element simulations were carried out with a foil: $h_{w}=50 \mathrm{~mm}$, $d=0.15 \mathrm{~mm}, m=3$ turns with connections and $h$ is various to adjust the porosity coefficient.

Thus, discrepancies between analytical and numerical methods can occur. Indeed, if the distance between the primary and secondary increases therefore, the leakage flux near the coil increases. It causes an increase of the eddy currents, and the current density of the internal layers becomes non-uniform, and hence Fr increases (see Fig. 8).
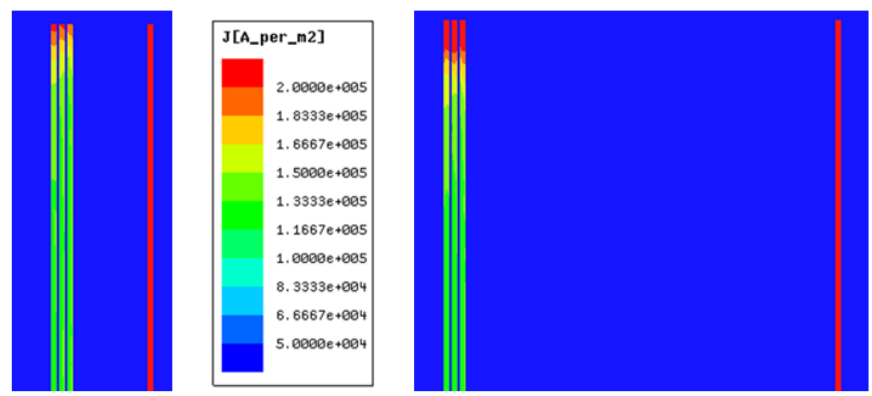

Figure 8 . The current density @ $20 \mathrm{kHz}$ for $2 \mathrm{~mm}$ and $10 \mathrm{~mm}$ between the primary and secondary with the same scale (Imposed current density is equal to $133 \mathrm{kA} \cdot \mathrm{m}^{-2}$ )

Moreover, if the coefficient of porosity decreases, the leakage flux is more important and so the eddy currents in the coil increase. Thus Fr increases. This is particularly true when both parameters are taken into account simultaneously (see Fig. 9).

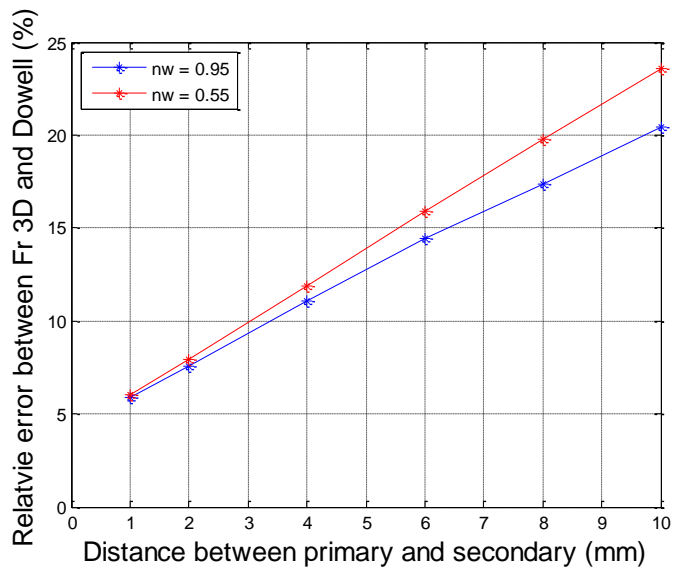

Figure 9 : Relative error between Fr 3D and Dowell (@ $20 \mathrm{kHz}$ ) as a function of distance between primary and secondary and for different porosity coefficient

It leads us to think then that analytical models are not suitable for high power medium frequency transformers because some of the assumptions are not respected (due to parameters that are not taken into account in the analytical models).

\section{COMParaison Of The Theoretical Models, MEASUREMENTS AND 3D SiMULATIONS}

The $R_{A C}$ as a function of frequency curves were measured with a Keysight E4990A and 16089B Medium Kelvin Clip Lead test fixture. Here, we analyze the influence of different porosity factors $\left(\eta_{w}=0.93 ; 0.7 ; 0.5\right)$, different distances between the primary and the secondary (10 up to $30 \mathrm{~mm}$ ).

The different foil windings characteristics are presented in Table II.

TABLE II. CONVERTER SPECIFICATIONS

\begin{tabular}{|c|c|c|c|c|c|}
\hline Name & $\begin{array}{l}\text { Number } \\
\text { of turns }\end{array}$ & $\begin{array}{l}\text { Thickness } \\
\text { (mm) }\end{array}$ & Name & $\begin{array}{l}\text { Number } \\
\text { of turns }\end{array}$ & $\begin{array}{l}\text { Thickness } \\
\text { (mm) }\end{array}$ \\
\hline F1 & 3 & \multirow{6}{*}{0.15} & F7 & 3 & \multirow{6}{*}{0.3} \\
\hline F2 & 5 & & F8 & 5 & \\
\hline F3 & 10 & & F9 & 10 & \\
\hline F4 & 15 & & F10 & 15 & \\
\hline F5 & 20 & & F11 & 20 & \\
\hline F6 & 25 & & F12 & 25 & \\
\hline
\end{tabular}

The Figs. 10 and 11 show the comparison between measurement results at different distances between primary and secondary winding, the theoretical models (Dowell [6], Ferreira [7] and Reatti [8]) and 3DFE results.

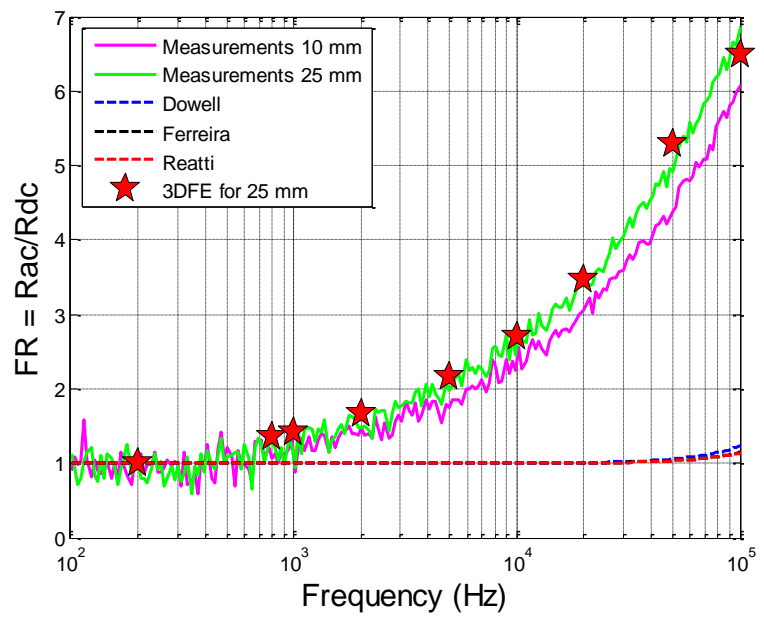

Figure 10. $\mathrm{Fr}=R_{A C} / R_{D C}$ as a function of frequency for different distances between primary and secondary for $\mathrm{F} 1$ : theoretical models, measurements and 3DFE

The curves $\mathrm{Fr}=R_{A C} / R_{D C}$, in function of frequency plotted in Fig. 10, show high discrepancies between analytical models (dashed lines) and measurements (solid curves).

The equations in [6]-[8] do not take into account the connections. For the F1 case, the number of turns is low (3 turns), then the resistance of the connections are of the same order of magnitude as the resistance foil. 
Increasing the number of turns reduces the discrepancies, as shown in Fig.11. In the case of F3 with 10 turns, the resistance connections can be neglected.

The current cannot spread uniformly throughout the height of the foil. Indeed, in Fig. 12, for F3, the current density of the intern layers is close to the input imposed current density value $\left(33 \mathrm{kA} . \mathrm{m}^{-2}\right)$. This is not the case for the F1 winding. This last phenomenon is not taken into account in the analytical models.

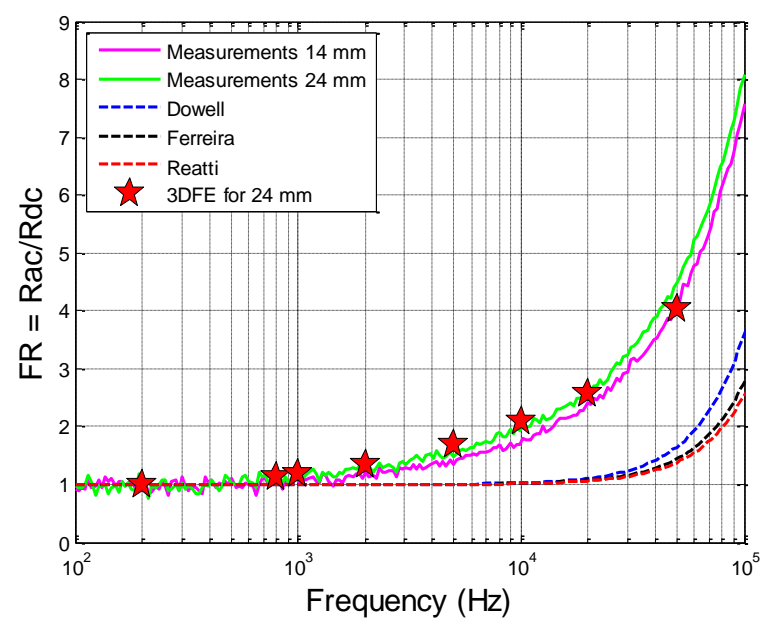

Figure 11. $\mathrm{Fr}=R_{A C} / R_{D C}$ as a function of frequency for different distances between primary and secondary for F3: theoretical models, measurements and 3DFE

It leads us to think that analytical models are not suitable for high power medium frequency transformers because some of the assumptions are not respected (due to parameters that are not taken into account in the analytical models). However, 3DFE calculations are in good agreement with measurements for foil windings. That means that $3 \mathrm{DFE}$ calculations have to be made instead of the analytical ones in order to predict accurately $R_{A C}$ in the design flow-chart.

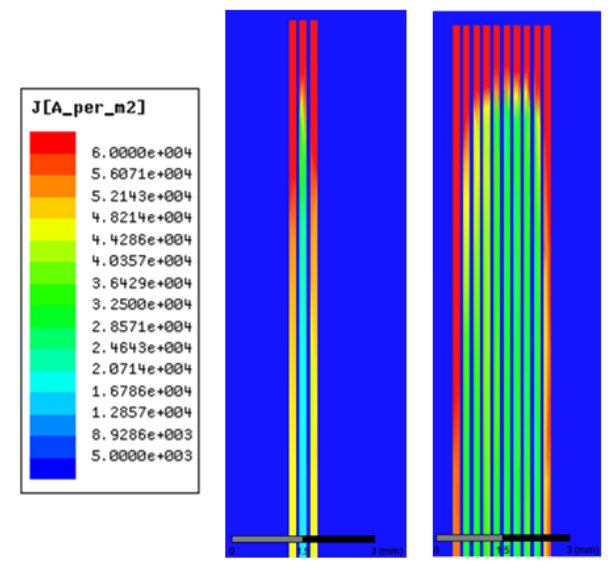

Figure 12. The current density @ 20 kHz for F1 (3 turns) and F3 (10 turns) with the same scale (Imposed current density is equal to $33 \mathrm{kA} \cdot \mathrm{m}^{-2}$ )

\section{APPLICATION FOR A MEDIUM FREQUENCY TRANSFORMER}

To check our design flow-chart, an MFT was designed. The chosen power converter is the Dual Active Bridge (DAB). The specifications of the converter are summarized in Table III. In order to manage the transfer of power, it exists several modulations to control a DAB non-resonant and resonant [11][13]. The TMF $180 \mathrm{kVA}$ is a core type transformer in ferrite 3C90, the characteristics are presented in Table IV.

TABLE III. CONVERTER SPECIFICATIONS

\begin{tabular}{|c|c|}
\hline Apparent power & $180 \mathrm{kVA}$ \\
\hline Active power & $100 \mathrm{~kW}$ \\
\hline Input voltage DC & $1.2 \mathrm{kV}$ \\
\hline Rated current AC & $150 \mathrm{~A}$ \\
\hline Switching frequency & $17 \mathrm{kHz}$ \\
\hline Turns ratio & $\mathrm{N} 2: \mathrm{N} 1=1: 2$ \\
\hline Leakage inductance $L_{\sigma}$ & As low as possible \\
\hline
\end{tabular}

TABLE IV. TRANSFORMER CHARACTERISTICS

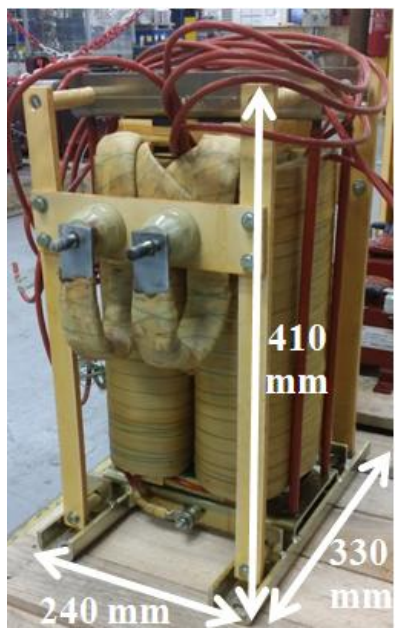

\begin{tabular}{|l|l|}
\hline Windings & $\begin{array}{l}\text { N1 }=14 \text { per column in series } \\
\text { N2 }=14 \text { per column in parallel }\end{array}$ \\
\hline Current density & $2,77 \mathrm{~A} / \mathrm{mm}^{2}$ \\
\hline Leakage inductance $L_{\sigma}$ & $\mathbf{6 , 1 4} \mu \mathrm{H}$ (measured) \\
\hline $\begin{array}{l}\text { Winding losses } \\
\text { (@ 150 A and 17 kHz) }\end{array}$ & $5 \mathrm{560}$ (calculated with 3DFE) \\
\hline
\end{tabular}

For the purpose of knowing $F r=R_{A C} / R_{D C}$ as a function of frequency, we carried out primary side short circuit measurements. In our case, we suppose that the $\mathrm{Fr}$ is the same for the primary and the secondary windings, because for each transformer column the number of layers (turns) is the same. So the resistance measured primary $R 1(f)$ side short circuit is equal to (7). 


$$
R 1(f)=F r(f) \cdot\left[R 1_{D C}+\left(\frac{N 1}{N 2}\right)^{2} \cdot R 2_{D C}\right]
$$

Where $R 1_{D C}$ and $R 2_{D C}$ are respectively the primary and secondary resistance in continuous. In order to calculate the $F r$, we use (8), the $F r$ is plotted in Fig. 13.

$$
F r(f)=\frac{R 1(f)}{R 1_{D C}+\left(\frac{N 1}{N 2}\right)^{2} \cdot R 2_{D C}}
$$

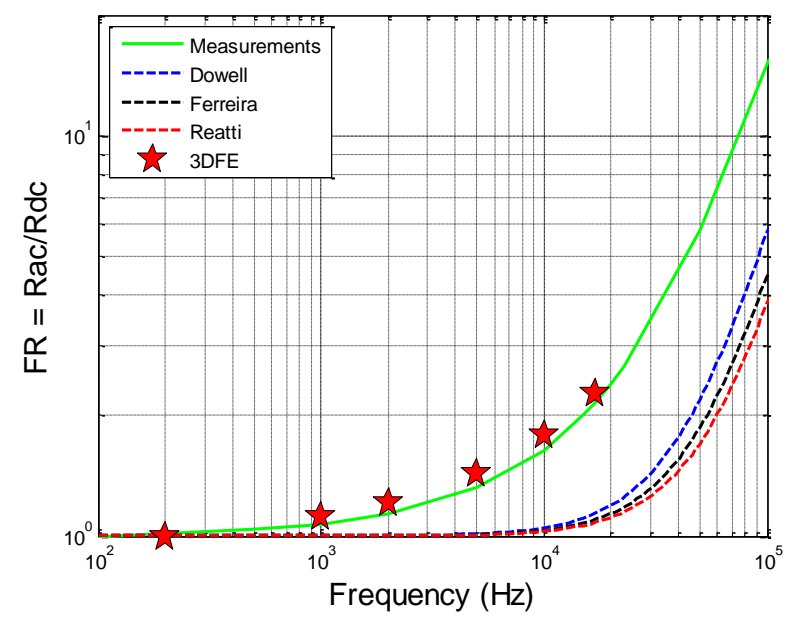

Figure 13. $\mathrm{Fr}=R_{A C} / R_{D C}$ as a function of frequency with the short circuit primary side measurements, theoretical models and 3DFE

For our type of application (high voltage transformers), we show high discrepancies between theoretical models and measurements. However, the results of 3DFE are in good agreement with measurements for the MFT. In our design flow-chart, if we were simply calculating the $R_{A C}$ only with the analytical models, then we would have underestimated the winding losses by $100 \%$ at $17 \mathrm{kHz}$. This error could lead to a mismatch with the rated efficiency and, moreover, it could lead to thermal problems.

\section{CONCLUSION}

In this paper, several analytical models have been tested applying them to the case of foil windings for high power medium frequency transformers.

In this case, the limits of different analytical models have been pointed out thanks to measurement and 3DFE calculations results. Indeed, the most critical parameters (connections, porosity coefficient and distance between the primary and secondary windings) to apply the analytical models were defined. Thanks to 3DFE simulations, the main causes of the discrepancies (ie. connection resistance, number of turns, current distribution homogeneity ...) were examined.

In order to validate our design flow-chart, an MFT prototype was designed for a high voltage and high power DC-DC application. We obtained the same kind of results. It leads us to think that for this application, if we use foil windings, the analytical models underestimate the alternative resistance. So engineers have to use 3DFE calculations to predict accurately the $R_{A C}$ for high power medium frequency transformers.

The increase of the relative error observed between Fr 3D and Dowell (which is a factor of the distance between primary and secondary and the porosity coefficient) also depends on the foil height, on the geometry of the windings and on the coupling magnetic coefficient. All these parameters are not taken into account in the different analytical models reviewed. In the next phase of research, some rules (e. g. safety factor, chart ...) to take into account these parameters will have to be developed.

The computing resources to solve these simulations are huge (e. g. in order to calculate the stars in Fig. 13, the simulation time is around one week to solve a mesh with 3 million elements). So, in the future, some rules to optimise the calculation time will also have to be developed.

\section{REFERENCES}

[1] C. J. Chou, Y. K. Wu, G. Y. Han and C.-Y. Lee, "Comparative Evaluation of the HVDC and HVAC Links Integrated in a Large Offshore Wind Farm - An Actual Case Study in Taiwan, "IEEE Trans. Industry Applications, vol. 48, pp. 1639-1648, Sept. 2012.

[2] D. Planson, D. Tournier, P. Bevilacqua, N. Dheilly, H. Morel, C. Raynaud, M. Lazar, D. Bergogne, B. Allard and J.-P. Chante, "SiC power semiconductor devices for new applications in power electronics," in Power Electronics and Motion Control Conference, EPE-PEMC 2008. 13th, 2008.

[3] G. Ortiz, J. Biela, D. Bortis and J. Kolar, "1 Megawatt, $20 \mathrm{kHz}$, isolated, bidirectional $12 \mathrm{kV}$ to $1.2 \mathrm{kV}$ DC-DC converter for renewable energy applications," in Power Electronics Conference (IPEC), 2010.

[4] G. Ortiz, J. Biela and J. Kolar, "Optimized design of medium frequency transformers with high isolation requirements," in IECON 2010 - 36th Annual Conference on IEEE Industrial Electronics Society, 2010.

[5] [Online]. Available: http://www.ansys.com

[6] P. Dowell, "Effects of eddy currents in transformer windings," Electrical Engineers, Proceedings of the Institution of, vol. 113, pp. 1387-1394, August 1966.

[7] J. Ferreira, "Appropriate modelling of conductive losses in the design of magnetic components," in Power Electronics Specialists Conference, PESC '90 Record., 21st Annual IEEE, 1990.

[8] A. Reatti and M. Kazimierczuk, "Comparison of various methods for calculating the AC resistance of inductors," IEEE Trans. Magnetics, vol. 38, pp. 1512-1518, 2002.

[9] G. Dimitrakakis and E. Tatakis, "Investigation of high frequency effects on layered coils," in Power Electronics and Motion Control Conference, EPE-PEMC 2008. 13th, 2008.

[10] J. Pollock, C. Sullivan and W. Lundquist, "The design of barrel-wound foil windings with multiple layers interchanged to balance layer currents," in Applied Power Electronics Conference and Exposition (APEC), Twenty-Sixth Annual IEEE, 2011.

[11] J. Everts, F. Krismer, J. Van den Keybus, J. Driesen et J. Kolar, "Optimal ZVS Modulation of Single-Phase Single-Stage Bidirectional DAB AC-DC Converters," IEEE Trans. Power Electronics, vol. 29, pp. 3954-3970, Aug. 2014.

[12] X. Li et A. Bhat, "Analysis and Design of High-Frequency Isolated Dual-Bridge Series Resonant DC/DC Converter," IEEE Trans. Power Electronics, vol. 25, pp. 850-862, Apr. 2010.

[13] Z. Pavlovic, J. Oliver, P. Alou, O. Garcia et J. Cobos, "Bidirectional Dual Active Bridge Series Resonant Converter with pulse modulation," in Applied Power Electronics Conference and Exposition (APEC), 2012 Twenty-Seventh Annual IEEE, 2012. 